\title{
Hand washing study in health care workers of a tertiary teaching hospital in Iran
}

\author{
Ali Majidpour ${ }^{1, *}$, Mohamad Hussein Shari'at ${ }^{2}$ \\ ${ }^{1}$ Infectious Diseases Department of Rasoul Akram Hospital, Iran University of Medical Sciences, Tehran, Iran \\ ${ }^{2}$ Iran University of Medical Sciences, Tehran, Iran
}

Email address:

alimajidpour@yahoo.com (A. Majidpour)

\section{To cite this article:}

Ali Majidpour, Mohamad Hussein Shari'at. Hand Washing Study in Health Care Workers of a Tertiary Teaching Hospital in Iran. European Journal of Preventive Medicine. Vol. 2, No. 1, 2014, pp. 16-19. doi: 10.11648/j.ejpm.20140201.13

\begin{abstract}
Hospital acquired infections are a worldwide problem and cross contamination transmission causes $40 \%$ of them while many of these infections are transmitted by healthcare workers. This study was designed to survey the prevalence of hand washing in health care workers (HCWs) of Rasoul Akram hospital, a tertiary level teaching hospital of Iran University of Medical Sciences (IUMS). This descriptive cross-sectional study was done on 350 healthcare workers, such as medical doctors, nurses, nurse' aide and other HCWs of the hospital. Questionnaire of hand washing made by WHO was used to collect data, and SPSS18 was used to data analysis. P value less than 0.05 was assumed significant. Oral consent was taken from participants before filling the questionnaire. Forty one percent were male, and average age of participants was 32.3 year $(\mathrm{SD}=6.8)$. Sixty five percent of the participants were routinely washing their hands. One hundred and twenty seven cases had been participated in hand washing workshop and $82.5 \%$ of them used hand washing routinely which was significantly more than nonparticipating $(\mathrm{p}<0.001)$. Almost $48 \%$ of males and $76.8 \%$ of females did hand washing, which indicates a significant difference between males and females. Nurses had highest rate of hand washing $(76.1 \%)$ and physicians had lowest $(47.9 \%)$ and this was significant $(\mathrm{p}<0.001)$. Sixty three percent of HCWs of internal medicine division , $50.8 \%$ of surgical ward, $69.5 \%$ of Emergency department, $87.5 \%$ of pediatric diseases section and $78.1 \%$ of gynecology section were doing routine hand washing.
\end{abstract}

Keywords: Hand Hygiene, Hand Washing, Hospital Acquired Infection, HAI, HCW

\section{Introduction}

Nosocomial infections (NI) are a worldwide problem with the prevalence of at least $5 \%$ in developed countries till $25 \%$ in developing world (1). It is estimated that crosssection transmission causes $40 \%$ of hospital acquired infections (2). Most of these infections are transmitted by contaminated hands of health care workers (3).

Epidemic study of NI clarified that many of these infections are related to not correct using of methods of decontaminations or not enough knowledge about these methods. With considering that hands of HCWs have great role in transmission of infectious agents and contaminated fomites from one patient to another, and from personnel to the patients, hand washing is the most important method in prevention of transmission .For this reason, it is recommended that hand washing must be emphasized routinely (4).

Although hand washing is one of the best ways of prevention of nosocomial infections, but many of HCWs don't attend to the methods of hand sanitation and in practice, the time and frequency of hand washing is much less than it is expected (5).Other studies show that in many of health centers, tendency of HCWs to wash their hands is unexpectedly low (6-7).

Samadipour A. et al showed that hand washing rate was $34.4 \%$ in internal medicine department, $21.3 \%$ in surgery ward, $16.7 \%$ in ICU unit and it was $16.6 \%$ between physicians (8). Rumgay S. et al reported that hand washing rate was $12.8 \%$ in physicians and $65.2 \%$ in nursing group (9). In study of Pittet D. et al average compliance of hand washing was $48 \%$ and noncompliance was the highest among physicians (10). The aim of this study is to know the rate and compliance of hand washing among health care workers of a tertiary teaching hospital in Tehran, Iran. 


\section{Methods}

This cross-sectional analytic study was carried out in health care workers of Rasoul Akram teaching hospital of Iran University of Medical Sciences in 2011 from Iran. 350 cases of health care workers including physicians, nurses, nurse's aide and other health care workers entered this study. The sample group was chosen by non random and convenience methods. And WHO questionnaire about Hand Hygiene, especially five moments of hand hygiene (before touching a patient, before a procedure, after a procedure or body fluid exposure risk, after touching a patient and after touching a patients' surroundings) was used for gathering data. Data were analyzed by SPSS version 18 and student ttest and Chi- square test were used for analysis .P value $<0.05$ considered significant. Oral consent was received from all participants and the data were protected confidentially.

\section{Results}

Among 350 cases $143(40.9 \%)$ were male and 207(59.1\%) were female. Mean age of cases was 32.3 years, ranging from 20 to 53 years. Forty two percent of cases were nurses, $35.4 \%$ doctors, $12.6 \%$ nurses aide and $10 \%$ other health care workers.

One hundred and eighteen cases were from internal medicine ward, 65 from surgical, 105 from emergency department, 8 from pediatrics diseases, 32 from gynecology and 22 cases from others.

One hundred and twenty seven cases had training course about hand washing. Sixty six percent washed their hands routinely and 119 of them did not. Almost 32\% used soap and water, $10.9 \%$ soap, water and antibacterial, $15.7 \%$ alcohol-based, 39.4\% soap, water and alcohol and 2.3\% used soap, water, antibacterial and alcohol. And $33.4 \%$ of them did hand washing before contact with patients, $40 \%$ before entrance isolated room, and $86.9 \%$ washed their hands when they had contaminated of hands. Also $42.6 \%$ of cases without considering the participation in training course washed their hands before contact with wound, 337(95.4\%) after contact with blood, 321(86.9\%) after contact with contaminated subjects, 306(87.4\%) after contact with wound and 218(62.3\%) after tracheal suctioning. From HCWs who did hand washing, 83.1\% washed their hands after physical contact with patients, $41.7 \%$ washed their hands after exit from isolated room, and $65.1 \%$ after taking of their gloves, $82.5 \%$ of cases who had been trained about hand washing, washed their hands routinely, but $55.6 \%$ of them who had not participated in hand hygiene training course, washed their hands, and the difference was significant $(\mathrm{p}<0.001)$ (table1).

Many of trained HCWs used soap, water and alcohol, but non trained used only soap and water that was statistically significantly different $(\mathrm{p}<0.001)$.

More than of $67 \%$ of trained HCWs washed their hands before contact with wounds but only $29 \%$ of non trained personnel did hand washing before contact with wound, which was significantly different $(\mathrm{p}<0.001)$.One hundred and eighteen of trained HCWs and 173 of non trained had hand washing after examination of patients that is statistically different $(\mathrm{p}<0.001)$.

Table 1. Comparision of handwashing based of having a training course

\begin{tabular}{lllllll}
\hline \multirow{2}{*}{$\begin{array}{l}\text { Training } \\
\text { course }\end{array}$} & \multicolumn{5}{c}{ Yes } & \multicolumn{3}{c}{ No } & \multicolumn{2}{c}{ Total } \\
\cline { 2 - 7 } & No. & Percent & No. & Percent & No. & Percent \\
\hline Yes & 104 & 81.2 & 23 & 18.8 & 127 & 36.3 \\
No & 124 & 55.6 & 99 & 44.4 & 223 & 63.7 \\
Total & 228 & 65.14 & 122 & 34.86 & 350 & 100 \\
\hline
\end{tabular}

After contact with blood, about $94 \%$ of trained and $96 \%$ of non trained HCWs washed their hands which had no significant difference $(\mathrm{p}>0.05)$. The hand washing between trained $(93.6 \%)$ and non trained $(84 \%)$ of HCWs after contact with wound was significantly different $(\mathrm{p}=0.005)$.Seventy four of trained and $66(29.5 \%)$ of non trained HCWs washed their hands before entering the isolated room, and the difference was significant $(\mathrm{p}<0.001)$. After taking off the gloves, $76.2 \%$ of trained and $58.9 \%$ of non trained HCWs washed their hands that was significantly different $(\mathrm{p}=0.001)$. Also $58.7 \%$ of trained and $19.2 \%$ of non trained of HCWs washed their hands before examination of patients and this difference was significant $(\mathrm{p}<0.001)$. After exiting the isolated room, $65.8 \%$ of trained and $28.1 \%$ of non trained did hand washing; this difference was significant $(\mathrm{p}<0.001)$. And finally $84.9 \%$ of trained and $49.5 \%$ of non trained washed their hands after tracheal tube suctioning $(\mathrm{p}<0.001)$.

In this study, hand washing rate in females was $76.8 \%$, which is significantly higher than males $(48 \%)(p<0.001)$. Before contact with wound, $34.2 \%$ of males and $48.3 \%$ of females did hand washing $(\mathrm{p}=0.006)$. Hand washing in males $(76.2 \%)$ was less than females $(87.9 \%)$ after examining the patient $(\mathrm{p}<0.001)$. Among males, $91.6 \%$ washed their hands after contact with blood, but this was $98 \%$ in females $(p=0.005)$. And the following situations, showed significant difference: After contact with wounds $(\mathrm{p}=0.001)$, before entrance to the isolated room $(\mathrm{p}<0.001)$, before examining the patients $(p<0.001)$, after exiting isolated room $(p<0.001)$ and after tracheal tube suctioning $(p<0.001)$. There was no difference between males and females after taking off gloves $(\mathrm{p}=0.2)$.

Forty eight percent of physicians, $76.1 \%$ of nurses, $70.5 \%$ of nurses aide, and $74.3 \%$ of other personnel washed their hands routinely, this indicates a difference between physicians and the others $(\mathrm{p}<0.001)($ table 2$)$.

The rate of hand washing was $62.7 \%$ in internal medicine ward, $50.8 \%$ in surgery department, $69.5 \%$ in emergency unit, $87.5 \%$ in pediatric and $75 \%$ in gynecology departments $(\mathrm{p}=0.03)$ (table 3$)$. There was no difference between age groups. 
Table 2. Handwashing based on occupation of HCWs in a teaching hospital

\begin{tabular}{lccc}
\hline \multirow{2}{*}{ Occupation } & Washing & No washing & Total \\
\cline { 2 - 4 } & No.(percent) & No.(percent) & No.(percent) \\
\hline Doctors & $59(48)$ & $65(52)$ & $124(35.42)$ \\
Nurses & $112(76.1)$ & $37(23.9)$ & $147(42)$ \\
Nurse' aide & $31(70.45)$ & $13(29.55)$ & $44(12.57)$ \\
Others & $26(74.3)$ & $9(25.7)$ & $35(10)$ \\
Total & $228(65.14)$ & $122(34.86)$ & $350(100)$ \\
\hline
\end{tabular}

Table 3. Hand washing based on department in a teaching hospital

\begin{tabular}{lcccccc}
\hline \multirow{2}{*}{ Department } & \multicolumn{2}{c}{ Washing } & \multicolumn{2}{c}{ No washing } & \multicolumn{2}{c}{ Total } \\
\cline { 2 - 7 } & No. & Percent & No. & Percent & No. & Percent \\
\hline $\begin{array}{l}\text { Internal } \\
\text { medicine }\end{array}$ & 74 & $62.71 \%$ & 44 & $37.29 \%$ & 118 & $33.7 \%$ \\
Surgery & 33 & $50.77 \%$ & 32 & $49.23 \%$ & 65 & $18.6 \%$ \\
Emergency & 73 & $69.52 \%$ & 32 & $30.48 \%$ & 105 & $30 \%$ \\
Pediatrics & 7 & $87.5 \%$ & 1 & $12.5 \%$ & 8 & $2.3 \%$ \\
Gynecology & 24 & $75 \%$ & 8 & $25 \%$ & 32 & $9.1 \%$ \\
Others & 17 & $77.27 \%$ & 5 & $22.73 \%$ & 22 & $6.3 \%$ \\
Total & 228 & $65.14 \%$ & 122 & $34.86 \%$ & 350 & $100 \%$ \\
\hline
\end{tabular}

\section{Discussion}

Hand hygiene can reduce healthcare associated infections and no attention to hand hygiene causes spread of drug resistant microorganisms and outbreaks of infections. Therefore promotion of hand hygiene helps to control of outbreaks in hospitals.

Hands can transport pathogens from contaminated stuff, health care workers, and some patients to other ones. Hand washing is one of the important methods of prevention of transmission of infection. In order to protect patients from nosocomial infections, hand washing must be done, all the times and regularly (4). Although hand washing is the most important procedure in preventing nosocomial infections but the hospital staff don't pay attention to ways of and how cleaning hands. They usually use non-standard methods for hand washing and they do much less frequent and spend less time on that, unlike they claim(5). In this study 350 cases of hospital staff were surveyed. $36 \%$ of them were trained in a course about hand hygiene; it means high percentage of HCWs in a teaching hospital in capital city had not participated in teaching course about hand washing. In this study only $65 \%$ of cases said they washed their hands; that is similar to study of Harris AD. et al that compliance of handwashing was less than $50 \%(11)$.

The rate of hand washing was higher in nurses, that is like the study of Sessa A. et al, who stated female nurses had more positive attitude about disinfection procedures than males (12).

The percentage of personnel who used hand hygiene procedures is like the study of Garcell HG et al in Havana , Cuba(13).

Although many of the healthcare workers specially physicians as a tertiary care center had awareness about the effectiveness of hand washing, but they did not perform in practice; It is similar to a study done in southwest Nigeria that showed good knowledge and attitude but poor practice among tertiary and secondary HCWs in Osogbo (14) and the study of Macdonald Duncan JM.et al (15).

Like the study of Caglar S. et al in NICU in Istanbul, Turkey(16), the difference between physicians and others was $\operatorname{seen}(\mathrm{p}<0.001)$.

The effectiveness of training course to improve hand hygiene compliance of HCWs is important (17), Naikoba S. et al showed that educational intervention had influence on hand washing behavior, but it was short-term (16). In our study, in many situations, hand washing was done more and more in trained HCWs -who used alcohol-based hand rub too- than non trained subjects; although this was not designed for long-term. This study showed that training courses workshop had significant effect on hand hygiene and participation of personnel in training course can be very important in reducing nosocomial infection.

In this study, physicians washed their hands less than other groups significantly. It is very important because physicians are the core of health care system and their practice has many effects on habits of other HCWs.

Hand washing in pediatric and gynecology department was significantly higher than other wards.

The age of HCWs had no effect on hand washing, while its rate was higher in females.

Samadipour A. et al showed that hand washing was 34.4\% in internal medicine department, $21.3 \%$ in surgery ward, $15.7 \%$ in ICUs and for physicians the rate was only $16.6 \%$ (8). In study of Rumgay S. et al hand washing rate was in physicians $12.8 \%$ and in nurses $65.2 \%$, just like our study(9).

Our study had several limitations: the sampling was not randomly, participants from different departments were not homogen, and facilities for hand washing were not enough in various parts of hospital.

\section{Conclusion}

This study shows that participating in hand hygiene training course has positive effect on HCWs' practice and females have higher rate of hand washing. It is suggested that training courses should be held routinely for all groups of HCWs.

Acknowledgements: Authors thank all of co-workers such as doctors, nurses, nurse' aide and other personnel of Rasoul Akram hospital who participated in this study. There was no ethical problem and all the participants had oral consent and the data were protected confidentially.

Interest of conflict: The authors do not have any interest of conflict in this study. 


\section{References}

[1] Edmond MB, Wenzel RP. Organization for infection control. In: Mandel GL, Bennet JE, Dolin R. Principles an practice of infectious diseases. $5^{\text {th }}$ ed. Philadelphia; Churchill Livingston .2009; 2988-2995.

[2] Weist K, Pollege K, Schulz I, Ruden H, Gastmeier P. How many nosocomial infections are associated with crosstransmission: a perspective cohort study in a surgical intensive care unit. Infect Control Hosp Epidemiol. 2002; 23: 127-32.

[3] Larson EL. APIC guideline for hand washing and hand antisepsis in health care settings. Am J Infect Control .1995; 23: 251-69.

[4] Cleave MC, Karen MJ. Nursing procedures .Paris : Spring house corp.1992.

[5] Fazel A. Evaluation of hand washing procedures in operation room. Post-graduate dissertation , Mashad University of Medical sciences, 1994(Full text in Persian)

[6] Anwar MA, Rabbi S, Masroor M, et al. Self-reported practices of hand hygiene among the trainees of a teaching hospital in a resource limited country. J Pak Med Assoc. 2009 Sep;59(9):631-4

[7] Rumbaua RO, Yu CT, Pena AC. A point-in-time observational study of hand washing practices of healthcare workers in the intensive care unit of St. Luke,s Medical Center. Phil J Microbiol Ifect Dis 2001; 30 (1):3-7

[8] Samadipour A, Daneshmandi M, Salari MM. Hand hygiene behavior in hospitals of Sabzwar city. J of Sabzwar UMS. 2009;15 (1): 59-64 (Full text in Persian)

[9] Rumgay S, McDonald S, Robertson CE. Hand washing patterns and infection control in the accident and emergency department. Archives of Emergency Medicine 1984; 3:157-9

[10] Pettit D, Mourouga P, Perneger TV, et al. Compliance with hand washing in a teaching hospital. Ann Intern Med. 1999;30:126-130

[11] Sessa A, Giuseppe GD, Albano L, et al. An investigation of nurses' knowledge, attitudes, and practices regarding disinfection procedures in Italy. BMC infectious diseases $2011 ; 11: 148-53$

[12] Garcell HG, Labrador LN, Perez CM, et al. Compliance with hand washing in intensive care unit in university hospital of La Havana. MEDICRIT.ORG. 2008;Volume 5:23-6

[13] Caglar S, Yildiz S, Savaser S. Observation results of handwashing by health-care workers in a neonatal intensive care unit. International Journal of Nursing Practice 2010;16:132-7

[14] Adepimpe Wasiu Olalekan, Asekun-Olarinmoye Esther Olufunmilayo, Bamidele James Olusegun, et al . A comparative study of awareness and attitude to nosocomial infections among levels of health care workers in southwestern Nigeri. Continental J. Tropical Medicine.2011; $5(2): 5-10$

[15] Macdonald D.JM, McKillop E.CA, Trotter S, et al. Improving hand-washing performance $-\mathrm{A}$ crossover study of hand-washing in the orthopedic department. Ann R Coll Surg Engl.2006 May ; 88(3):289-91

[16] Naikoba S, Hayward A. The effectiveness of interventions aimed at increasing hand washing in healthcare workers - a systematic review. J Hosp Infect. 2001 Mar; 47(3):173-80

[17] C Martin-Madrazo, A Canada-Dorado, M A Salinero-Fort, et al. Effectiveness of a training programme to improve hand hygiene compliance in primary health care. BMC Public Health 2009; 9:469S 